\title{
EL BANCO DE ESPAÑA: ASPECTOS JURIDICO-FINANCIEROS
}

\author{
EVA ALIAGA AGULLO
}

Es innegable que uno de los hechos más importantes que han caracterizado la vida económica española de los últimos años, ha sido el creciente protagonismo asumido por el Banco de España en el funcionamiento de la economía nacional.

La promulgación en 1980 de la Ley de Organos Rectores, supuso el reconocimiento de un ámbito funcional específico de libre desenvolvimiento para el Banco de España, en orden a la consecución de un fin que la ley le atribuye como propio, cual es, el de salvaguardar el valor del dinero.

En tal sentido, el Banco de España al que se concede una indudable discrecionalidad técnica y operativa, se convierte en un ente público de perfiles difícilmente encajables en la ordenación positiva española, en marcha hacia una efectiva independiencia real respecto de la Administración del Estado garantizada por una autonomía orgánica, un ámbito propio funcional independiente en determinados aspectos del Gobierno, una misión institucional propia atribuida por la Ley y una indudable capacidad normativa. No obstante, la nueva configuración orgánica y funcional del Banco de España como consecuencia de la adaptación que, en su caso, habrá de efectuar al Estatuto de Banco Central Europeo, exigirá que el elgislador español modifique su actual Estatuto jurídico.

El análisis del Banco de España desde el mundo del Derecho Financiero a través de las relaciones que éste guarda con los principios propios de esta disciplina y con los institutos jurídicos de la que ella se ocupa, es lo que conforma el núcleo central de esta investigación.

En el estudio de los aspectos jurídico-financieros de la actividad del Banco de España abordamos, como tema fundamental, la delimitación de este instituto en base a la pluralidad de funciones desempeñadas por el mismo.

El análisis, desarrollo y sistematización jurídico-positiva de cada uno de los aspectos que componen el ámbito funcional del Banco de España, permite concluir que es un Instituto de carácter complejo que desempeña en su actividad funciones de diversa índole y naturaleza, dentro de las cuales y como parcela específica de las mismas, se pone de relieve la existencia de ciertas manifestaciones jurídico-financieras que responden, en definitiva, al desarrollo de las funciones de carácter financiero atribuidas por el ordenamiento jurídico al Banco de España.

En primer lugar, el Banco de España es un Instituto colaborador de la Hacienda. Al mismo tiempo, el Banco de España, ente con funciones financieras propias se convierte en un Instituto independiente, dotado de un ámbito financiero propio manifestado en la capacidad para ser titular de los derechos económicos resultantes 
de la aplicación de sus recursos propios, así como para asumir las necesidades públicas cuya satisfacción la encomienda el ordenamiento jurídico.

No obstante, el conjunto de funciones financieras que configuran jurídicamente la actividad financiera del Banco de España, son sólo un aspecto de su gestión pública. Junto a ellas y en la medida que es compatible con éstas aparece un interés recaudador, esto es la consideración del Banco de España como fuente productora de sus ingresos para el Tesoro Público.

Por ello, la Hacienda del Banco, configurada de modo autónomo, que responde a una idea organizadora distinta de la del Estado, es en definitiva, una Hacienda interna de la Hacienda del Estado porque los rendimientos de su actividad son derechos económicos de la Hacienda Estatal y constituyen una parte del haber de la misma.

Finalmente, hemos de poner de relieve que el Banco de España como Instituto financiero independiente deberá someterse a los principios materiales y formales que presiden el ejercicio de las funciones financieras públicas, así como a los mecanismos de control que respecto de la actividad financiera ha elaborado el Derecho Público.

La acomodación normativa a las exigencias planteadas en nuestra Tesis Doctoral, perfilan el futuro de una entidad cuyos aspectos jurídico-financieros hemos pretendido destacar en el presente trabajo. 